\title{
Multimodality - The Driving Force for Engineering Undergraduates in a Course of Technical English
}

\author{
Arancha G. Pinar \\ University Center of Defense, Polytechnic University of Cartagena (CUD-UPCT), Spain
}

Copyright $\bigcirc 2019$ by authors, all rights reserved. Authors agree that this article remains permanently open access under the terms of the Creative Commons Attribution License 4.0 International License

\begin{abstract}
Multimodality, as an inter-disciplinary approach that understands communication and representation to be about more than language, and where the coexistence of traditional and new modes and media acquires great relevance, is likely to be one of the focuses of English for Specific Purposes (ESP) research. Regarding one central component of ESP, namely learner's needs, a multimodal approach appears optimal, as it prioritises the technological preferences of learners who might be intrinsically motivated to learn English. Teachers, therefore, need to be attentive to this fact and incorporate technology and the affordances of the Internet as important component in any L2 classroom. The ESP curriculum could benefit from a learning environment with a diverse deployment of teaching and learning modes which lead the English lecturer to constantly reappraise the suitability of one mode over another and carry out some type of 'gain and loss' analysis. There is now an increasing number of studies that focus on this analysis to explore what might be gained and what might be lost if the design of an ESP curriculum moves from representation through writing to representation mainly through image. Incorporating digital technologies within the ESP classroom without ignoring the importance of more traditional pedagogies that place the book at the core of the language learning process might turn to be the most suitable ESP approach in a course of English for undergraduates of Engineering.
\end{abstract}

Keywords Multimodality, Mode, Need Analysis, Affordance, Aptness, Gain and Loss

\section{Introducing Multimodality}

The term first appeared in the mid-1990s and was used by different authors in different works and disciplines; Charles Goodwin [1] used it in a seminar article on Ethnomethodology and conversation analysis, which was included in the Journal of Pragmatics in 1998. Shortly after that, O'Halloran also started to use the term 'multisemiotic' to refer to the multimodal character of Mathematics texts.

Multimodality has its origin, to a great extent, in the work of Michael Halliday on the social semiotic theory of communication. In Language as Social Semiotic (1978), Halliday [2] develops Systemic Functional Linguistics (SFL), a social semiotic theory of language. This theory is constructed on the assumption that language is a social semiotic system, and brings to the fore the social perspective of meaning and the notion of meaning as choice. Halliday conceived language as a set of options that configures what people can and cannot do with language in a specific social context. However, for him, language is not the only semiotic resource that frames and shapes society and culture. Modes, which are understood as socially and culturally shaped resources for making meaning, also play an essential role in communication:

There are many other modes of meaning, in any culture, which are outside the realm of language. These will include both art forms such as painting, sculpture, music, dance, and so forth, and other modes of cultural behaviour that are not classified under the heading of forms of art, such as modes of exchange, modes of dress, structures of the family, and so forth. These are all bearers of meaning in the culture. Indeed, we can define a culture as a set of semiotic systems, as a set of systems of meaning, all of which interrelate. [3]. p.4

Gunther Kress and Robert Hodge [4] drew on Halliday's work on language to study the meaning potential of other modes. In Social Semiotics, the authors stated that social semiotics "is primarily concerned with human semiosis as an inherently social phenomenon $[\ldots]$ it is concerned with the full range of semiotic forms, semiotic texts and semiotic practices" (p.261). Several works have expanded the ideas from linguistics, and have adapted Halliday's notion of meaning, using a Systemic Functional Theory (SFT) to research how both linguistic and non-linguistic resources combine to create meaning. Van Leeuwen's 
Sound, Music, Speech [5] focused on the materiality of the semiotic resources of sound and researches the semiotic potential of different modes and genres such as classical music, film soundtracks and advertising jingles. Martinec [6] studied the semiotic of action, movement and gesture; O'Toole [7] centred on the semiotics of images; O'Halloran [8] studied how images, language, and mathematical symbolism accommodate mathematical texts. Kress and Van Leeuwen focused on the potentiality of images in Reading Images [9], a work, which was later developed in Multimodal Discourse: The Modes and Media of Communication [10] to explore the semiotic potentials of space and architecture, multimedia, voice and music. In this book, Kress and Van Leeuwen outlined a framework that applies to different modes, and set a theory of multimodal communication (p.2):

We move towards a view of multimodality in which common semiotic principles operate in and across different modes, and in which it is therefore quite possible for music to encode action, or images to encode emotion. This move comes [...] because we want to create a theory of semiotics appropriate to contemporary semiotic practice. In the past, and in many contexts still today, multimodal texts (such as films or newspapers) were organised as hierarchies of specialist modes integrated by and editing process. Moreover, they were produced in this way, with different, hierarchically organised specialists in charge of the different modes, and an editing process bringing their work together. Today, however, in the age of digitisation, the different modes have technically become the same at some level of representation, and they can be operated by one multi-skilled person, using one interface, one mode of physical manipulation, so that he or she can ask, at every point: 'Shall I express this with sound or music?. 'Shall I say this visually or verbally?' and so on.

All these early works on multimodality shared a common objective; they tried to explain that different means of meaning making are not unrelated but often appear together. Their aim was to account for the synergy and multimodal wholes created from different types of modes (gesture, sound, speech, gaze, proxemics, and sound). Other disciplines before had only captured the way of meaning making that fell within their field of research; Linguistics in speech and writing, Semiotics in image, Musicology in music, among others.

Multimodality is an interdisciplinary approach that understands communication and representation to be more than about language [11]. One important concern of multimodality is the analysis of spoken and written language. However, the major interest is in studying how language is nested in the multimodal ensemble. A multimodal orientation deprives language of a superior status, and points to the fact that language, in the same way as any other mode, cannot be attended in isolation as Jewitt, Bezemer and O'Halloran explain [12, pp. 17-18]:
Language has a different status in different communities and in the repertoires of different people. Language also has different status in different contexts of use. Much, if not most, communication happens without the use of speech or writing [...]. In many circumstances, speech and writing are not available or indeed suitable for what needs to be communicated, and yet those who find themselves in those situations are perfectly capable of jointly achieving quite complex tasks that heavily rely on communication.

\section{Multimodality in Mainstream Education and Pedagogy}

One of the first calls that prompted the need to rethink learning models and underscored the necessity to design new frameworks to redirect teaching and learning was addressed by the New London Group [13] (Cazdem, Gee, Kress, Luke, Cope, Kalantzi, among others). This team of leading literacy educators and researchers presented the article 'A Pedagogy of Multiliteracies: designing social futures', after a year of 'exhaustive discussions', and referred to it as an unfinished 'programmatic manifesto' (p.63). They aimed to problematize the social and cultural reshaping of the communicational landscape that globalization and new technologies had brought about. A new approach to literacy and pedagogy, which they referred to as "multiliteracies", could stretch the limitations of traditional approaches that did not encompass the shifting semiotic landscape that transformed the ways in which people communicated and transformed traditional ways of producing and distributing information (p.61):

In this article, we attempt to broaden this understanding of literacy and literacy teaching and learning to include negotiating a multiplicity of discourses. We seek to highlight two principal aspects of this multiplicity. First, we want to extend the idea and scope of literacy pedagogy to account for the context of our culturally and linguistically diverse and increasingly globalized societies and for the multifarious cultures that interrelate and the plurality of texts that circulate. Second we argue that literacy pedagogy now must account for the burgeoning variety of text forms associated with information and multimedia technologies. This includes understanding and competent control of representational forms that are becoming increasingly significant in the overall communication environment, such as visual images and their relationship with the written word, for instance, visual design in desktop publishing or the interface of visual and linguistic meaning in multimedia.

Against this backdrop of transformation and globalisation, the authors urged the acceptance of new relationships among different modes, specifically geared to the articulation between visual image and the word, as an available resource for making meaning in the classroom. 
Language, according to them, was not the only mode of representation and learning. It was clear that there were many dimensions of a student's learning style that should be considered. Visual and aural stimuli may appeal more to students who preferred to learn more visually than it would to those who preferred to learn only verbally (using videos, maps, graphs, charts, cartoons, posters, diagrams, graphic organisers, picture books, drawing, board games, projects, experiments and group activities).

The model of pedagogy advocated by these researchers also challenged the conventional relationship between the teacher and the learner, and gave them active roles in social change. The teacher and the learner became active participants. This influential manifesto on new prospects for teaching and learning literacy triggered, from 2000 onwards, an interest in multimodality among researchers in different educational contexts. It is worth mentioning that multimodal studies were carried out by Kress, Jewitt, Ogborn and Tsatsarelis, [14] and Reiss, Boulter and Tunnicliffe [15] in Science education, O'Halloran, K. $[16,17,18]$ in Mathematics education, Burn, and Durran [19], Crescenzi, Jewitt, and Price [20], in Media education in schools, among many others.

The availability of digital technologies these days broadens the scope of multimodality. Communication has been multimodal for a long time. People have usually resorted to a wide range of modes to communicate, and texts have always been multimodal. There has always been a great variety of modalities. However, the introduction of digital technologies takes a significant turn to theorise and analyse how, for instance, moving and still images are configured and fit in with other modes, such as writing, speech, and layout.

Multimodality and its potential for researching digital technologies allow the systematic description of modes and their semiotic resources. Screen-based texts enable new multimodal configurations where still images, moving images, colour, layout, sound, writing and speech, body movement, and gestures play a part in communication, interpretation, and representation. This way of communication is particularly meaningful for literacy education, where digital communication technologies give rise to new challenges and demands for teachers and students. Students of the $21^{\text {st }}$ century might become active participants, become sign makers who exploit combinations of different modes to discover and identify new reading paths. Linking, rearranging elements, interpreting new configurations and organisations through digital layering and hyperlinking, searching and validating information are some of the skills that digital multimodal technologies impose these days. New technologies, therefore, have triggered considerable research on multimodality in educational settings. Multimodality, as is mentioned above, is not new because there has always been a great diversity of modalities. However, technological developments enable the configuration of complex modal ensembles that have an impact on meaning making, and in education. There is an increasing interest in researching how modes are deployed in digital texts, how these new configurations might affect the way students write and read on screen, what kind of strategies they use [21], and how they process different modes within digital texts [22]. Content in digital environments, is differently displayed and new reading patterns arise [23]. The new reshaping of practices enabled by the use of digital technologies makes their study especially relevant to multimodality.

Teachers and researchers alike are interested in determining how students can best benefit from new technologies in the classroom, and in which meaningful ways the interweaving of digital technology leads to beneficial learning experiences. Since the screen is the "culturally dominant medium in many parts of the globe, and for many members of numerous societies around the world" [24, p.7], it seems reasonable to focus pedagogical research interest on how meaning making is realised through linguistic representation, visual representation, audio representation, spatial representation, and gesture [13].

Multiple studies have dealt with the affordances of the deployment of new technologies in the second language classroom. Kern [25] highlights the importance of technology as a way of reshaping and rethinking the conception of language, communication and society. This analysis can help teachers figure out the best way to use technology in language learning and teaching. Thorne and Payne [26] describe the evolution of communication technologies, the changes in communicative activity, and the pedagogical possibilities these technologies have brought about in second and foreign language contexts. Their analysis focuses on blogs, wikis, podcasting, and advances in intelligent computer-assisted language learning. Walsh [21] highlights the potential of combining the teaching of print-based literacy with digital technologies in a range of curriculum areas. Teachers, according to Walsh [21, p. 227], "have to ensure that with the incorporation of digital communication technologies, basic aspects of reading, writing, language learning, grammar, spelling and punctuation are still explicitly taught".

Future sections focus on the implications of the 'revolution' that, among other issues, as is stated by Kress $[27$, p.6] involves a movement "from the centrality of writing to the increasing significance of image", and also a change "from the centrality of the medium of the book to the medium of the screen" (p.6) in educational contexts. Hyland [28, p. 3) has emphasised this revolution in traditional academic practices as follows:

While in the past the main vehicles of academic discourse were written texts, now a broad range of modalities and presentation forms confront and challenge students' communicative competence. They must learn rapidly to negotiate a complex web of 
disciplinary-specific text types, assessment tasks and presentational modes (both face-to-face and online) in order first to graduate, and then to operate effectively in the workplace.

\section{Multimodality in English for Specific Purposes}

Multimodality has made educational institutions reappraise traditional aspects of the educational environment, and institutions that teach languages seem to increasingly include multimodal perspectives in their curricula. Multimodality research questions, therefore, now seem to be positioned alongside more traditional ESP research questions. As Prior notes [29], these are "questions of language forms in monomodal frames": Does meaning conveyed now through space, visual images and language simultaneously make understanding easier? What are the benefits and limitations of attending to different modes? Does a multimodal approach to EST learning motivate students?

Particularly, research in the field of multimodality focuses on exploring the incorporation of the visual mode into students' texts to understand what kind of visual-verbal linkages arise. These studies focus on researching the way digital technologies enable new multimodal configurations and how students make meaning from these. Multimodal literacy prevails these days and the student who is not skilled in this competence might be at a disadvantage in different educational and work contexts. The language lecturer is, therefore, advised to bear this in mind in order to develop this multimodal competence along with other competences in the L2 classroom. Only then will the student be able to distinguish which the most appropriate mode for specific purposes of representation and communication is.

As multimodality allows for more opportunities to engage interactively, learners are no longer passive recipients of language information. This new communicative landscape entails a reassessment of the different ways that language skills have been traditionally approached in order to offer language learners optimum opportunities that allow them to engage with texts that are increasingly multimodal and frequently digital. The processes of talking, listening, reading and writing, Walsh [21] notes, "are different because of the way digital technology has changed social communication practices. Differences occur, not only in interaction between different modes in the processes of reading or writing on screen or online, but in the interaction between students". The following sections offer an overview of the relationship between ESP and the key areas of speaking, listening, reading and writing.

\subsection{ESP Listening and Multimodality}

The focus of ESP listening instruction has been on working skills such as lecture comprehension. Vandergrift and Goh [30] highlight that to enhance comprehension, language learners can engage in metacognitive processes that include strategies to manipulate and transform the spoken input, manage and regulate cognitive processes and emotions, and exploit resources to assist comprehension.

Research into ESP listening has not only concentrated on students' reliance on metacognitive strategies to enhance listening comprehension. Miller [31], for instance, conducted a large-scale ethnographic study with a group of second language engineering students, and stated that both the students and their lecturers needed to "consider how listening comprehension can be sustained, if not improved". To keep students motivated, Miller notes (p.9), "lectures need to be interesting to all students in order to maintain their motivation levels, and they also need to be accessible to maintain their concentration levels". Second language engineering students showed preferences for the type of language and lecturer's teaching techniques. Regarding the use of English features in lectures, students highlighted simplification, pronunciation and specific content. The use of visuals and the reliance on body language, in particular, showed students' inclination towards a pedagogy that does not solely rely on language. As students reported in Miller's study [31, p.27], “simply presenting the information in what is considered a traditional language manner does not satisfy the students, nor will it allow them access to the complex information presented in a second language".

Miller's study [31, p.23] also investigated the teaching strategies that students valued highly. These strategies included: the use of a variety of teaching styles, the lecturer's demonstration of interest in the subject, short lectures, creation of a relaxed atmosphere, regular testing of lectures content and keeping control of the lecture.

Rapid developments in the area of digital technology have significant implications for how the listening process is carried out these days in educational settings as O'Halloran, Tan, and Smith [32, p.256] point out:

Changes in higher education, especially in the use of digital technology, have revolutionized traditional academic practices, with an increasing recognition of the need for students and teachers to develop multimodal competencies across a range of communicative platforms.

The emergence of new multimodal resources (e.g. online academic lectures, websites, and video resources) diverts the focus of attention. It is not only to verbal input comprehension but to non-verbal input that EST learners must pay attention to. It is both about listening and about watching. A multimodal approach to listening assumes that learners can benefit from input that integrates verbal modes with non-verbal modes such as hand/arm gesturing, direction of gaze, postural stance and facial expression. Accordingly, researchers and scholars point to the fact 
that students need, as Archer notes [33, p. 211], a pedagogy that supplies them with "systematic technical knowledge of the ways semiotic resources are deployed in meaning-making". In this sense, Doering, Beach and O'Brien [34, p. 43), highlight that it is important to think "multimodally and semiotically".

The introduction of digital resources in the L2 classroom makes a detailed analysis of non-verbal modes and their interaction with verbal modes in specific communicative situations compulsory. Gestures, for instance, have been extensively studied by McNeill [35] with the purpose of evidencing that they might enhance listening comprehension, assist in clarifying verbal meanings, and convey additional information. Gestures that are accompanied by speech can contribute to the listener's comprehension by developing in the listener a cognitive simulation or mental representation of the message. McNeill [35] classifies hand gestures into four different types: beat, deictic, iconic, and metaphorical. Beat gestures are associated with the discourse-pragmatic content of the utterances, and are commonly used by speakers to focus attention and check comprehension. Deictics are pointing gestures commonly used to refer to specific objects or when calling attention to some point in a presentation slide. Iconic gestures are related to meaning and used when the speaker is describing concrete objects or events. Metaphoric gestures are usually used to encode abstract ideas.

Facial expressions have also been researched in connection to the ways that can express attitude and stance. Ekman [36] underscored the importance of learning to identify emotions in order to improve communication in all kinds of situations, and to deal with emotional responses. Facial expressions are understood to be one of the primary and most effective resources to engage audiences emotionally. There is a significant interest in analysing some facial movements such as nodding, lip movement, and raising eyebrows, as these co-occur with speech. Hood and Forey [37] analysed a set of plenary presentations at an academic conference to explore the different ways speakers drawing on speech, on gesture and facial cues, construed "relationships of solidarity with the audience" (p. 291) and expressed attitude, graduation and engagement (p.304). Among their findings, the authors concluded that raising of eyebrows may perform a discourse marker function, an expression of explicit positive effect as "thanks", which might be accompanied by a smile. A downward turned mouth and dropped head amplified a negative appreciation. A speaker's surprise, in turn, was accompanied by raised eyebrows, a half smile and a nod.

The interplay of verbal and non-verbal features can be studied in detail in academic lectures in digital format, and in online courses delivered in university settings on Internet platforms. Nowadays, online lectures and courses constitute a major teaching and learning resource in scientific and technical fields, the field of engineering being a case in point. Some of the institutions that offer video recordings of lectures are MIT (the Massachusetts Institute of Technology) and its OCW (Open Courseware), and Yale's Open Courses website. Massive Open Online Courses or MOOCs have become additional resources that teachers and learners frequently resort to. These are freely accessible and open-licensed short courses that meet high academic standards, and are offered fully online. The benefits of lectures and courses in digital format are numerous. Among these, the flexibility afforded to students who can regard these as an 'out-of school' experience, allowing them to set their own pace and view these repeatedly.

TED Talks, dealing with a wide range of topics given by speakers on the cutting edge of their fields of expertise, might constitute another example of authentic material that combines verbal and non-verbal modes. In terms of language, speakers in these talks focus on transmitting knowledge while conveying immediacy, dynamism, enthusiasm, excitement, and emotion. Language is one of the most important modes in these talks, partly because it is a mode shared by the speaker and the listener allowing the recreation of the speakers' ideas in the audience's minds. Rather than starting with one's own language and concepts, speakers often start their talks with the audience's language, concepts and values. Delivery of ideas is, therefore, smooth and engaging. For students in the field of technology, efficient delivery of clear instructions is the centre stage, and TED Talks can be suitable communication guidelines that undergraduates of engineering can emulate.

If students' attention while listening and watching is directed to the modal salience and aptness in these talks, they might listen attentively while making meaning from this crafted ensemble of modes. Language in most cases carries the conceptual meaning and paralanguage and body language the affective load. The emergence of engagement, empathy, curiosity, and connection among students might arise from this connection.

Visual is another key component of engineers' works. Many TED Talks use photographs, graphs, tables, animation, video and illustrations. These visuals achieve in the majority of cases a twofold objective: they increase the aesthetics of the presentation and upgrade the explanation. ESP students are encouraged to use well-thought-out visuals in their presentations as these can help explain and clarify concepts and processes that are hard to describe. The visualisation of part of the content of the oral presentations offers students a "range of genres of texts to appreciate and interpret, and an awareness of visual supplies a more critical understanding of the complexities of images" [23]

\subsection{ESP Writing and Multimodality}

Recent social and technological developments mean 
genre encompasses new multimodal genres, like videoconferences, blogs, video blogs, and emails among others. Hyland and Hamp-Lyons [38] draw attention to this change, a "tectonic shift" in Kress' terms [39]. This change has led language teachers to find themselves:

involved in the far-reaching changes brought to academic life by the advent of electronic communication technologies. It is, of course, difficult to ignore the considerable impact of computer-mediated interaction on academic and professional life. For many of use in the developed world, this has transformed the ways we write, the genres we create, the ways we get and send information and increasingly, the ways we teach.

The presentation slide genre increasingly used in diverse academic settings, Microsoft's Power Point being by far the most commonly used, is among the emergent multimodal digital genres. Since its launch in 1990, PowerPoint has become an integral part of pedagogy as a whole and in tertiary contexts in particular. An alternative presentation software is Prezi. This presentation technology allows students to effectively communicate ideas in a clear, appealing and engaging way. Different colours, fonts, canvas designs and types of media can be chosen by students. Unlike Power Point, Prezi can present a story line in both a linear and a free-flowing way. Additionally, Prezi presentations can be published allowing students to work online.

The design of these presentations need a catchy title. A title sequence identifies a text and 'sells' it to the audience. It may be explicit about the text's genre, content, audience and purpose, or it may disguise this to provoke curiosity. The title must also be aesthetically appealing in terms of colour, font type, etc. Students, on the other hand, are required to make oral presentations, most of which use presentations slides. This widespread practice has brought about a new landscape for producing oral, written and visual texts. Students, drawing on the design of this type of presentations software construct meaning in multimodal dynamic texts, and move across multiple modes of text design (visual, spatial, gestural and audio modes), enhancing and exploring new creative possibilities, and creating texts that involve design and construction of meaning. The use of different organisational structures, vocabulary choice, visual representations and colour in these presentation slides allow them to express cultural, educational, linguistic and disciplinary identities in ways the written texts alone cannot. Tardy's [40] study of the verbal and visual expressions in PowerPoint presentation slides designed by four engineering undergraduates led her to conclude that students could "portray themselves as members of their disciplinary communities through organizational structures, lexical choices, visual images, and slide colour".

The visual mode in most engineering presentations assists students in explaining concepts, and in showing results through the deployment of tables, graphics, schematic diagrams, videos and numeric images in ways where language by itself is limited. The presentation slides, additionally, can lead to effective peer assessment opportunities [41]. The slides that students design throughout the course have an audience in mind. The design process might entail the development of students' evaluating and multimodal skills to assess other classmates' designs. This process might lead to a collaborative learning environment.

Images have different functions, and the choice of images in students' presentations is of great important. Thus, students need to make sure that what kind of information they want to transmit, and what type of image best presents what they want to transmit; bar charts are best used to compare quantities, pie charts show proportions of the whole, timelines represent history and, scatter plots designate density and frequency [33]. Students in a multimodal environment can enjoy agency and autonomy, and drawing on verbal (lexical choices, organizational structures), and visual choices (e.g. still and moving images, colour and layout) they can become active designers of different learning tasks. They construct meaning, exploit combinations of different modes, and express, as Tardy notes [42, p. 321], their identities and ideologies showing themselves:

as members of disciplinary communities and as unique individuals. They project their own habitus (Bourdieu, 1977), or set of dispositions formed through repeated encounters over times-as students, researchers, scientists, computer game players, parents, first-language and second-language writers, and so on.

Designing, composing and representing knowledge in this dynamic way might also, as is discussed in further sections, help undergraduates of Engineering enhance other skills, such as reading, through students' research and analysis of information. This multimodal way of writing and composing texts might assist students that 'lack confidence in their language skills and may be hesitant to challenge generic forms in the verbal mode' [42, p. 334]. The visual mode, as Kress notes, [27] provides "new freedoms" for authors:

The new freedoms for authors and readers bring changes in practices: The question of rhetoric makes my subjectivity in this instance of communication now an issue each time anew. Presenting myself as the appropriate subject for this occasion of communication means that I am each time performing, staging, myself. When there is no stability to authorship or readership that has to be produced each time for this audience, on this occasion. So, whether in choice of genre, in choice of medium or in choice of mode subjectivity is at issue.

The technical report, which is another genre that engineering undergraduates need to be proficient in, might integrate complex layouts, and visual elements (e.g. colour, image, layout). This might change the way writing 
is presented and the way learners construct meaning. New technologies, as Jewitt [43, p.321] states, "emphasize the visual potential of writing in ways that bring forth new configurations of image and writing on screen: font, bold, italic, colour, layout, and beyond". As Kress highlights [44, p.6], writing is becoming some type of "assembling according to designs in ways which are overt, and much more far-reaching, than they were previously".

Students' slides designs and their composition of technical reports and essays position ESP learners as creators and designers of new and dynamic multimodal texts. Writing in ESP contexts departs from the regulated conventions these days, and puts language and features of design (e.g. layout, use of image and graphics) on an equal footing. The notion of design and the agency of the individual, as Kress notes [27, p.20], are central in current teaching environments, and in the writings of EST learners:

We need the notion of design, which says: In this social and cultural environment, with these demands for communication of these materials, for that audience, with these resources, and given this interest of mine, what is the design that best meets these requirements? Design focuses forward; it assumes that resources are never entirely apt but will need to be transformed in relation to all the contingencies of this environment now and the demands made.

\subsection{ESP Speaking and Multimodality}

Technology is increasingly found these days in the ESP classroom and is becoming a more valuable tool to develop students' oral presentation skills. The plethora of websites now offering oral presentations by experts in a great variety of fields illustrate this trend. The key challenge for teachers is to design approaches to learning and teaching that draw on technology and that explicitly teach students the affordances and constraints of different modes. Rowley-Jolivet notes [45, 46], that these approaches to learning must involve a focus on linguistic features, audio and visual choices. In this regard, online TED Talks might be suitable tools that include all these features. TED teaches how to communicate by linking different modes (i.e. the visual, gestural, verbal, written and spatial) to technological production. Students construct communication when they attentively observe and make meaning from this ensemble of modes. Additionally, students might be involved in the higher-order thinking task of analysing and evaluating these talks, as these demand some kind of critical multimodal analysis through creative engagement. While being in charge of this process, students actively invest in the learning process, and might make the learning material their own. This fact is likely to turn the learning process into an enjoyable experience, and motivation might be generated from within rather than through extrinsic motives (i.e. grades, rewards). There are other different ways TED talks might find their way into the course of technical English beyond the simulation of a form of speaking delivery. TED, as a source of ideas and information, can be used to make students discover topics of their interest. After the screening and general classroom discussion, students can work in groups to answer a series of questions, which are designed to make students discover that the same talk can generate a set of different reactions.

Beforehand, however, ESP teachers must show students the ways these lectures can be deconstructed so that they can be introduced to "the functions of individual semiotic resources and their interactions in digitally enabled, multimodal texts", and learn how speakers use linguistic, visual and audio resources to engage the audience [32, $\mathrm{p}$. 265].

\subsection{ESP Reading and Multimodality}

The deployment of multimodal modes in both L2 textbooks and digital screen-based texts generates considerable research these days related to how readers understand content and construct knowledge from multimodal ensembles ([10, 47]. Authors such as Danielsson and Selander [48] contend that multimodal texts need a multimodal approach that analyses how different semiotic resources, and their combination express content and construct knowledge.

The increasing integration of language and multimodal resources (e.g. colour, layout, font, image and spatiality) has become a widespread feature in English language learning (ELL) textbooks, and technical English books have not been an exception. This trend might lead teachers to assess the possibilities and constraints of visual and non-linguistic resources in textbooks. Teachers need to make students aware that writing is no longer the dominant representational resource and that it combines with different multimodal resources to construct knowledge. Additionally, teachers must advise today's undergraduates to consider issues such as the saliency of some resources, the type of roles that different illustrations might play, the kind of content students might expect from headings and illustrations, the type of information images facilitate; are they used to visualise or to simplify a complex phenomenon or reasoning? Do images add new, complex information? Do different resources give the same, overlapping, or supplementing information? [48]. Another important aspect to consider in multimodal texts relates to the aptness of representing different types of content (e.g. photos, tables, graphs). The concept of aptness [27, p.19] refers to the appropriateness of resources according to a specific purpose:

The new media make it possible to use the mode that seems most apt for the purpose of representation and communication: If I need to represent something best done as image I can now do so, similarly with writing. Aptness of mode to the characteristics of what is 
represented is much more a feature now - it is a facility of the new media. Aptness of mode and what is represented is not the only issue: Equally significant now is the aptness of fit between mode and audience. I can now choose the mode according to what I know or might imagine is the preferred mode of the audience I have in mind.

New digital multimodal configurations similarly stir up interest in relation to the type of reading processes students must undertake. Does the reading of multimodal texts entail different processes than the reading of print-based texts? What are the reading paths students create and take? Which mode is privileged by students when confronted with the wide configuration of modes (writing, image, colour, and layout)? Which mode carries which kind of information? In this sense, the theory of multimodality maintains that the concurrent processing of different modes of text, image, sound and gesture in digital texts is a different function from the linear, sequential, reading of print-based texts. Kress [44] points to the fact that the screen and multimodal texts originate new ways of communication, where word and image hold different logics; writing is based on the logic of succession in time, and images are based on the logic of display in space. Accordingly, the reading of visuals would involve a different reading process than the reading of words.

The difference between reading print-based texts and the reading of images and multimodal texts has been examined by Walsh [49]. The main differences between the two types of reading relates to the processing of modes. Multimodal texts require students to use various senses (i.e. visual, tactile, hearing, and kinaesthetic). This multimodal reading process makes learners interact and be involved in multisensory activities that include browsing, decoding, hyper-linking, interpreting, navigating, searching, and analysing [21]. Print-based text demands that the reader solely uses the visual and some tactile sense. In print-based texts, the words tell; in multimodal texts, the images show. Print-based texts have a verbal style that includes layout, font, punctuation, word play and intonation. Multimodal texts have a visual style that includes choice of medium, animation, frames, links, and hyperlinks. The verbal imagery in print-based texts includes descriptions, images, symbolism, metaphor, simile and alliteration. The visual imagery in multimodal texts includes use of colour, motifs, icons, repetition. Finally, the reading path in print-based texts is mostly linear and sequential, and in multimodal texts is non-linear and non-sequential.

The language learner becomes nowadays a 'reader-viewer' who needs both to draw inferences from written texts [9] and to adopt strategies that allow him or her to discuss visual images (i.e. modality, framing, composition). Serafini [47] points out that learners these days: must learn to navigate the design of print-based and digital texts, including the left to right orientation of English language texts, and understand the role that charts, graphs, diagrams, visual images, fonts, design elements, and illustrations encountered in picture books, informational texts, graphic novels, websites, and advertisements play as readers construct meaning in transaction with these multimodal texts. (p. 28)

The use of TED Talks in classroom as learning tools offers numerous advantages in the ESP class to teach and learn any of the four skills. The reading skill, in particular can be developed in different ways. TED website provides the transcript for every talk, and teachers can consider the possibility of allowing students to listen to the talk in class while reading the transcript. This is an approach to fostering fluency that researchers such as Winke, Gass and Sydorenko [50] have demonstrated to be beneficial for gaining reading speed and word recognition accuracy.

However, it is not only attention to the verbal mode that teachers should encourage. TED Talks, as is previously described, could be deconstructed in such a way that students notice how every different mode deployed on stage contributes to the construction of meaning. Speakers' postures, gestures, facial expressions, the way they use space, and their power points have clearly relevant roles in the process of communication. Each of these modes is a piece of the discourse mechanism and should be given due attention.

To inform relevant ESP multimodal pedagogy, lecturers should urge students to reflect on the functions and the meaning different modes perform in digital texts. Lecturers should also encourage students to develop a multimodal competence, and decide whether visuals expand, enhance, or describe the related print [51, p.67]. It might be also important to make sure students not only engage in the superficial learning of technology but also, as Ryan, Scott and Walsh [41, p. 10] note, that they engage in the "critical issues of how the media can be used to communicate particular messages to particular audiences [...]. This involves the strategic insertion of discussion of exemplar texts into the teaching process in such a way that student autonomy is not limited".

\section{Conclusions}

Technology imposes itself upon different language teaching contexts, and teachers have no choice but to learn how different technologies work, and how to handle the limitless amount of varied and authentic materials that one can find outside the classroom. The measureless and unrestricted information that the Internet displays leads teachers to inevitably consider old questions that have been long asked by L2 researchers. Thus, to select texts or technological tools one should recall some questions that Dudley-Evans and St. John already considered regarding 
the selection of reading texts and course material [52]: "Who chooses? / What is chosen? [53, p. 99], and what do you need/want from the course?" The affordance of technology on the other hand is extensive, as it is applicable both in the ESP classroom, and as an essential tool to enhance learners' independent language learning outside the classroom.

The learning environment multimodality imposes with a diverse deployment of teaching and learning modes might lead the teacher to reflect on the suitability of one mode over another and carry out some type of 'gain and loss' analysis. In this regard, Jewitt highlights [43, p. 327), "rather than ask what is best, the book or the screen', it seems more reasonable to ask what is the best for what purpose". Thus, a multimodal approach can foster work collaboration and a community of practice, as it favours a context where students, as Lave and Wenger note [53, p. 27], "share a concern, a set of problems, or a passion about a topic, deepen their knowledge and expertise in this area by interacting on an ongoing basis". A pedagogy that draws on different modes to construct meaning and to communicate might allow the performance of different tasks in small groups, the oral presentation that student groups prepare, being by far, one of the most demanding task requiring collaborative efforts. Authenticity, alignment with students' digital preferences and a collaborative nature of work might seem, on the surface, to meet the requirements necessary to have enthusiastic and motivated language learners. Meaning conveyed through the visual and the verbal mode simultaneously might make understanding easier in students' classroom presentations. The choice of a particular visual in these presentations can be an issue that should be carefully considered. Multimodal concepts such as modal affordance (i.e. different modes can present different potentials for making meaning), aptness (i.e. some modes may be more apt for a specific purpose than others) and visual salience (i.e. the specific ways different elements in a visual layout such as colour, size and contrast appear in order to capture the viewer's attention) are key concepts that students should be aware of when designing their power points, as these will have a determining role in the overall performance .The visual mode can assist students in explaining concepts, and in showing results through the deployment of tables, graphics, schematic diagrams, videos and numeric images in ways that language by itself is limited. One suitable option, therefore, with reading and similarly with listening, writing and speaking seems to be to incorporate digital technologies within the course of technological English without ignoring the importance of more traditional pedagogies that place the book at the core of the language learning process. A cautious ESP approach might point to maintaining the balance between traditional and multimodal literacy. It is when different types of methodologies are provided that L2 learners' different learning styles can be met. Diversity and flexibility of pedagogy might also promote learners' motivation and engagement.

\section{REFERENCES}

[1] C. Goodwin. Action and embodiment within situated human interaction. Journal of Pragmatics, No.2, 1489-522, 1998.

[2] M. Halliday. Language as Social Semiotic: The Social Interpretation of Language and Meaning, Edward Arnold, London, 1978.

[3] M. Halliday \& R. Hasan. Language, Context, and Text: Aspects of Language in a Social-Semiotic Perspective, Deakin University, Geelong, Victoria, 1985.

[4] G. Kress, \& R. Hodge. Social Semiotics, Polity Press, Cambridge, 1988.

[5] T. Leeuwen. Speech, Music, Sound, Macmillan, London, 1999.

[6] R. Martinec. Types of Processes in Action. Semiotica, Vol. 3, No.120, 243-268, 2000.

[7] M. O'Toole. The Language of Displayed Art, Leicester University Press, London, 1994.

[8] K.L. O'Halloran. Interdependence, Interaction and Metaphor in Multisemiotic Texts, Social Semiotics, Vol. 3, No. 9, 317-54, 1999.

[9] G. Kress \& T. Leeuwen, T. Reading Images: The Grammar of Visual Design, Routledge, London, 1996.

[10] G. Kress \& T. Leeuwen. Multimodal Discourse: The Modes and Media of Contemporary Communication Discourse, Arnold, London, 2001.

[11] C. Jewitt (Ed.). The Routledge Handbook of Multimodal Analysis. Routledge, London, 2009.

[12] C. Jewitt, J. Bezemer\& K.L.O'Halloran. Introducing Multimodality, Routledge, London, 2016.

[13] New London Group. A pedagogy of multiliteracies. In B. Cope and M. Kalantzis (Eds.), Multiliteracies: Literacy Learning and the Design of Social Futures, Macmillan, Melbourne, 9-38, 2000.

[14] G.Kress, C. Jewitt, J. Ogborn \& C. Tsatsarelis.Multimodal Teaching and Learning: The Rhetorics of the Science Classroom. Bloomsbury Academic, New York, 2001.

[15] M.J.Reiss, C. Boulter \& S.D. Tunnicliffe. Seeing the natural world: A tension between pupils' diverse conceptions as revealed by their visual representations and monolithic science lessons. Visual Communication, Vol. 1, No. 6, 95-110, 2007.

[16] K.L. O'Halloran. Mathematical Discourse: Language, Symbolism and Visual Images, Continunn, London and New York, 2005.

[17] K.L. O'Halloran. The Language of Learning Mathematics: A Multimodal Perspective. The Journal of Mathematical Behavior, 40, 63-74, 2015. 
[18] K.L. O'Halloran. Mathematics as Multimodal Semiosis. In E. Davis \& P. J. Davis (Eds.), Mathematics, Substance, and Surmise, Springer, Berlin, 287-303, 2018.

[19] A. Burn \& C. Durran. Media Teaching: Language, Audience and Production, Wakefield Press, Adelaide, 2008.

[20] L. Crescenzi, S. Price, C. Jewitt. The role of physical action and touch with touch screen technologies in the play and learning of preschool children. The Australian Journal of Language and Literacy, Vol.2, No.3, 86-95, 2014.

[21] M. Walsh. Multimodal literacy: What does it mean for classroom practice. Australian Journal of Language and Literacy, Vol.3, No.33, 211-223, 2010.

[22] M. Prensky. Digital natives, digital immigrants, part 1. On the Horizon, Vol. 5, No. 9, 1-6, 2001.

[23] J. Rowsell. Working with Multimodality, Routledge, London, 2013.

[24] D. Johnson \& G. Kress. Globalisation, literacy and society: Redesigning pedagogy and assessment. Assessment in Education, Vol 1, No. 10, 5-14, 2003.

[25] R. Kern. Perspectives on technology in learning and teaching languages, TESOL Quarterly; Vol 1. No.40, 183-210, 2006.

[26] S. Thorne \& J. Payne. Evolutionary trajectories, Internet-mediated expression, and language education. CALICO Journal; Vol. 3, No. 22, 371-397, 2005.

[27] G. Kress. Gains and Losses: New Forms of Texts, Knowledge, and Learning. Computers and Composition, Vol. 1, No. 22, 5-22, 2005.

[28] K. Hyland. English for Academic Purposes: An Advanced Resource Book, Routledge, London, 2006.

[29] P. Prior. Multimodality and ESP Research. In B. Paltridge \& S. Starfield (Eds.), The handbook of English for specific purposes, Wiley-Blackwell, Malden, 2013.

[30] L. Vandergrift \& C. Goh. Teaching and Learning Second Language Listening: Metacognition in Action, Routledge, New York, 2012.

[31] L. Miller. Engineering lectures in a second language: What factors facilitate students' listening comprehension? Asian EFL Journal, Vol. 2, No. 11, 8-30, 2009.

[32] K.L. O’Halloran, Tan \& B. Smith. Multimodal approaches to English for academic purposes. In K. Hyland \& P. Shaw (Eds.), The Routledge Handbook of English for Academic Purposes, Routledge, London \& New York, 256-269, 2016.

[33] A. Archer. Multimodal texts in Higher Education and the implications for writing pedagogy. English in Education, 44, 201-213, 2010.

[34] A. Doering, R. Beach, R. \& D. O’Brien. Infusing multimodal tools, and digital literacies into an English Education program, English Education, Vol. 1, No. 40, 41-60, 2007

[35] D. McNeill. Hand and mind: What gestures reveal about thought, University of Chicago Press, Chicago, 1992.

[36] P. Ekman. Emotion in the human face. Cambridge University Press, Cambridge, 1982.
[37] S. Hood \& G. Forey. Introducing a conference paper: Getting interpersonal with your audience. Journal of English for Academic Purposes, 4, 291-306, 2005.

[38] K. Hyland \& L. Hamp-Lyons. EAP: issues and directions. Journal of English for Academic Purposes, Vol. 1, No. 1, 1-12, 2002.

[39] G. Kress. Before writing: Rethinking the paths to literacy, Sage, London, England, 1997.

[40] C. M. Tardy. Discourses of internationalization and diversity in US universities and writing programs. In Transnational Writing Program Administration, Utah State University Press, An imprint of University Press of Colorado, 243-262, 2014.

[41] J. Ryan, A. Scott, A. \& M. Walsh. Pedagogy in the multimodal classroom: An analysis of the challenges and opportunities for teachers. Teachers \& Teaching; Vol. 4, No. 16, 477-489, 2010.

[42] C. M. Tardy. Expressions of disciplinarity and individuality in a multimodal genre. Computers and Composition; Vol. 3, No. 22, 319-336, 2005.

[43] C. Jewitt. Multimodal 'reading' and 'writing' on screen. Discourse Studies in the Cultural Politics of Education; Vol. 3, No. 26, 315-331, 2005.

[44] G. Kress. Literacy in the new media age. Routledge, London, 2003.

[45] E. Rowley-Jolivet. . Visual Discourse in Scientific Conference Papers: A Genre-Based Study. English for Specific Purposes, Vol.1, No. 21, 19-40, 2002.

[46] Rowley-Jolivet, E. Different visions, different visuals: a social semiotic analysis of field-specific visual composition in scientific conference presentations. Visual communication, 3, 145-175, 2004.

[47] F. Serafini. Reading multimodal texts in the 21st century. Research in the Schools, Vol. 1, No. 19, 26-32, 2012.

[48] K. Danielsson \& S. Selander. Reading Multimodal Texts for Learning - a Model for Cultivating Multimodal Literacy, Designs for Learning, Vol. 1, No. 8, 25-36, 2016.

[49] M. Walsh. Literacy education. In J. D. Wright (Ed.), International Encyclopaedia of the Social \& Behavioural Sciences ( $2^{\text {nd }}$ edition), Elsevier, Oxford, 246-250, 2015.

[50] P. Winke, S. Gass \& T. Sydorenko, T. The effects of captioning videos used for foreign language listening activities. Language Learning \& Technology, Vol. 1, No. $14,65-86,2010$.

[51] P. Abraham \& M. Farías. Reading with eyes wide open: Reflections on the impact of multimodal texts on second language reading. Íkala, Revista de Lenguaje y Cultura, 2017, Vol.1, No. 22, 57-70, 2017

[52] T. Dudley-Evans \& M. St. John. Developments in ESP: A multi-disciplinary approach. Cambridge University Press, Cambridge, 1998.

[53] J. Lave, \& E. Wenger E. Situated Learning: Legitimate Peripheral Participation, Cambridge University Press, Cambridge, 1991. 